\title{
PENGENALAN RAS BERDASARKAN HIDUNG DAN MULUT MENGGUNAKAN GRAY LEVEL CO-OCCURRENCE MATRIX
}

\author{
Ema Rachmawati*1, Nur Azizah Agustina ${ }^{2}$, Febryanti Sthevanie ${ }^{3}$ \\ ${ }^{123}$ Fakultas Informatika, Universitas Telkom \\ Email: 1'emarachmawati@telkomuniversity.ac.id, 2nurazizahagustina@gmail.com, \\ ${ }^{3}$ sthevanie@telkomuniversity.ac.id \\ *Penulis Korespondensi
}

(Naskah masuk: 17 November 2020, diterima untuk diterbitkan: 19 Juli 2021)

\begin{abstract}
Abstrak
Ras dapat digunakan untuk mengkategorikan manusia dalam populasi atau kelompok besar. Oleh karena itu, pengenalan ras dapat berguna untuk mempermudah dalam mengidentifikasi seseorang dan membantu dalam mempersempit lingkup pencarian. Penggunaan wajah sebagai dasar pengenalan ras mengarahkan penelitian pada identifikasi penggunaan bagian wajah yang berpengaruh signifikan terhadap kinerja pengenalan ras. Pada penelitian ini bagian wajah berupa hidung dan mulut diidentifikasi untuk digunakan sebagai dasar pengenalan ras Mongoloid, Kaukasoid, dan Negroid. Ciri Gray Level Co-occurrence Matrix (GLCM) diekstrak dari bagian hidung dan mulut untuk selanjutnya diklasifikasi menggunakan Random Forest. Hasil eksperimen menunjukkan bahwa penggunaan ciri gabungan dari hidung dan mulut mampu menghasilkan kinerja sistem yang paling baik jika dibandingkan penggunaan hidung atau mulut saja.
\end{abstract}

Kata Kunci: Ras, Wajah, Hidung dan Mulut, Gray Level Co-occurrence Matrix, Random Forest.

\section{RACE RECOGNITION BASED ON NOSE AND MOUTH USING GRAY LEVEL CO- OCCURRENCE MATRIX}

\begin{abstract}
Race can be used to categorize humans in populations or large groups. Therefore, racial recognition can be useful to make it easier to identify a person and help narrow the scope of the search. The use of faces as a basis for race recognition directs research on identifying the use of facial parts that significantly influence the performance of race recognition. In this study, the face parts of the nose and mouth were identified to be used as a basis for the recognition of the Mongoloid, Caucasoid, and Negroid races. The Gray Level Co-occurrence Matrix (GLCM) feature is extracted from the nose and mouth to be classified using Random Forest. The experimental results show that the use of combined features of the nose and mouth is able to produce the best system performance compared to the use of the nose or mouth only.
\end{abstract}

Keywords: race, face, nose and mouth, Gray Level Co-occurrence Matrix, Random Forest.

\section{PENDAHULUAN}

Wajah manusia adalah salah satu karakteristik paling penting dalam pengawasan visual, karena dapat memberikan informasi yang sangat berguna misalnya untuk keperluan pengawasan (Momin \& Tapamo, 2016). Beberapa informasi yang dapat diambil dari wajah manusia antara lain jenis kelamin, umur, ras, dan ekspresi wajah. Berbeda dengan usia, jenis kelamin, dan ekspresi wajah, pengenalan ras tidak dapat dengan mudah disamarkan. Salah satu penggunaan hasil pengenalan ras ini antara lain pada proses pencarian citra. Dengan pengenalan ras maka ruang pencarian dalam basisdata akan dipersempit, sehingga proses pencarian menjadi lebih sederhana. Selain itu, pengenalan ras juga penting dalam pemodelan penyakit manusia karena ras sangat terkait dengan variasi genetik yang spesifik pada suatu populasi (Masood, Gupta, Wajid, Gupta, \& Ahmed, 2018).

Banyak penelitian yang dilakukan dengan menggunakan wajah sebagai dasar dari pengenalan, baik pengenalan gender (Alrashed \& Berbar, 2013)(Manesh, Ghahramani, \& Tan, 2010), etnis (Rehman, Khan, Siddiqi, Khan, \& Khan, 2018), ras 
(Momin \& Tapamo, 2016), maupun estimasi wajah (Hosoi, Takikawa, \& Kawade, 2004). Dari berbagai penelitian tersebut, penggunaan Gray Level CoOccurrence Matrix (GLCM) cukup populer sebagai metode ekstraksi ciri pada pengenalan berbasis wajah (Alrashed \& Berbar, 2013) (Eleyan \& Demirel, 2011)(Rehman, Khan, Siddiqi, Khan, \& Khan, 2018). Klasifikasi gender yang dilakukan oleh Alrashed dkk (2013) menggunakan mata sebagai bagian wajah yang diambil cirinya mampu menghasilkan akurasi sampai 98,49\%. Selain itu, penelitian pengenalan etnis yang dilakukan Rehman dkk (2018) mampu membuktikan bahwa GLCM menunjukkan kinerja yang sangat baik. Eksperimen dilakukan menggunakan bagian kulit dari wajah. Sementara, Eleyan \& Demirel (2011) membuktikan dalam penelitiannya bahwa GLCM mampu mengurangi beban komputasi algoritma dan pada saat yang sama mempertahankan tingkat pengenalan yang tetap tinggi. Hal ini disebabkan oleh proses kuantisasi yang membantu dalam menekan noise citra pada tingkat keabuan yang lebih tinggi. Dari penelitian tersebut terbukti bahwa GLCM adalah metode yang Tangguh untuk pengenalan wajah dengan kinerja yang cukup kompetitif.

Di sisi lain, sejumlah penelitian telah dilakukan untuk mengetahui pengaruh dari penggunaan bagianbagian wajah alih-alih keseluruhan wajah pada kinerja pengenalan. Sthevanie dkk (2018) menggunakan daerah periorbital wajah yaitu gabungan dari daerah periocular mata dan daerah hidung untuk diambil cirinya. Klasifikasi gender yang dilakukan oleh Alrashed dkk (2013) juga menggunakan mata dan bukan keseluruhan wajah sebagai dasar pengenalan. Momin dan Tapamo (2016) menjelaskan bahwa hidung dan mulut adalah indikator yang lebih baik dari kelompok etnis dibandingkan dengan mata.

Oleh karena itu, pada penelitian ini penulis berusaha mengetahui kinerja GLCM pada pengenalan ras khususnya pada 3 (tiga) ras besar di dunia, yaitu Mongoloid, Kaukasoid, dan Negroid, dengan ekstraksi ciri pada bagian hidung dan mulut saja. Kinerja pengenalan dibandingkan dalam hal penggunaan bagian wajah, jenis ciri GLCM, dan classifier (Random Forest dan k-Nearest Neighbor). Hasil eksperimen pada 967 citra menunjukkan bahwa penggunaaan 5 (lima) ciri GLCM pada bagian hidung dan mulut mampu memberikan kinerja terbaik.

Susunan makalah adalah sebagai berikut. Kajian terkait terdapat pada bagian 2, deskripsi sistem yang dibangun terdapat pada bagian 3 , eksperimen dan analisis dipaparkan pada bagian 4 , dan ditutup dengan kesimpulan pada bagian 5 .

\section{KAJIAN TERKAIT}

Ras merupakan perangkat yang dapat digunakan untuk mengelompokkan manusia ke dalam populasi besar dan berbeda, atau kelompok berdasarkan keturunan, karakteristik fenotipik, geografi, fisik, etnis, dan status sosial (Rehman, Khan, Siddiqi,
Khan, \& Khan, 2018). Terdapat tiga ras besar di dunia yaitu Mongoloid atau yang biasa disebut ras Asia, Kaukasoid, dan Negroid. Perbedaan karakteristik dari wajah yang dimiliki oleh ras Mongoloid, Kaukasoid dan Negroid dapat dilihat pada Tabel 1 (Hosoi, Takikawa, \& Kawade, 2004).

Beberapa penelitian dilakukan untuk mengenali ras atau etnis. Manesh dkk (2010) melakukan penelitian mengenai klasifikasi gender dan ras untuk pengenalan wajah. Metode yang digunakan yaitu Gabor dan menggunakan SVM untuk klasifikasi kelas. Dataset yang digunakan adalah FERET dan PEAL dengan menghasilkan akurasi 96\%. Yang dan Ai (2007) menggunakan metode Local Binary Pattern (LBP) dan AdaBoost, akurasi yang dihasilkan mencapai 97\%. Momin dan Tapamo (2016) menggunakan ekstraksi ciri Gabor sedangkan metode klasifikasi yang digunakan adalah $K$-Means, Naive Bayesian (NB), Multilayer Perceptron (MLP), Support Vector Machines (SVM). Klasifikasi dilakukan terhadap 2 (dua) kelas (Asia dan Non Asia), 3 kelas (Asia, Putih, dan Hitam), dan 4 kelas (Asia, India, Putih, dan Hitam). Hasil eksperimen menunjukkan bahwa hidung dan mulut adalah indikator yang lebih baik dibandingkan dengan mata dalam pengenalan etnis ini. Sthevanie dkk (2018) melakukan klasifikasi ras Mongoloid dan Non Mongoloid menggunakan daerah periorbital wajah yaitu gabungan dari daerah periocular mata dan daerah hidung. Dataset yang digunakan diambil dari FERET sebanyak 160 citra. Akurasi sangat baik diperoleh menggunakan metode LBP. Rehman dkk (2018) melakukan pengenalan 4 (empat) etnis dari enam dataset berbeda. Metode yang digunakan yaitu gabungan histogram dengan GLCM. Bagian dari wajah yang diambil cirinya yaitu bagian kulit.

Tabel 1. Karakteristik wajah dari tiap ras [6]

\begin{tabular}{cl}
\hline Jenis Ras & \multicolumn{1}{c}{ Karakteristik Wajah } \\
\hline & Mata: Lipatan sempit \\
& Hidung: rendah, lebar rata-rata \\
Asia & Bibir: rata-rata penuh \\
(Mongoloid) & Rambut: rambut tipis dan lurus atau sedikit \\
& bergelombang \\
& Kulit: kekuningan \\
& Mata: kelopak mata ganda, palung air mata terbuka, \\
& besar \\
& Hidung: Mancung \\
& Bibir: tipis, kencang \\
& Bentuk wajah: pusat wajah menonjol ke luar, \\
Eropa & berbentuk baji, wajah panjang \\
(Kaukasoid) & Rambut: bergelombang atau keriting, tubuh tebal dan \\
& rambut wajah (laki-laki) \\
& Kulit: terang atau cokelat \\
& Mata: besar dengan palung air mata terbuka \\
& Hidung: lebar, rendah \\
Afrika & Bibir: tebal, mulut terentang \\
(Negroid) & Bentuk wajah: kepala panjang \\
& Rambut: ikal ketat atau gelombang berat \\
& Kulit: gelap \\
&
\end{tabular}

Di sisi lain, Hosoi dkk (2004) melakukan penelitian untuk memperkirakan citra wajah tahun 
1991, dengan tingkat akurasi yang dicapai yaitu: Asia: 96,3\%, Eropa: 93,1\%, Afrika: 94,3\%. Dari hasil eksperimen ditemukan kesalahan pengenalan terjadi pada citra wajah dengan kacamata, yang disebabkan oleh keberadaan bingkai kacamata atau cahaya yang memantul dari lensa kacamata. Eleyan dan Demirel (2011) menggunakan GLCM untuk pengenalan wajah dan membandingkannya dengan metode PCA, LDA, wavelet Gabor, dan LBP. Akurasi yang sangat baik diperoleh Alrashed dkk (2013) pada sistem pengenalan wajah berdasarkan mata menggunakan metode GLCM.

\section{SISTEM YANG DIUSULKAN}

Terdapat 2 (dua) skema yang dibangun pada sistem pengenalan ras ini, yaitu skema pelatihan dan pengujian. Pada skema pelatihan yang dapat dilihat pada Gambar 1, sistem akan mengolah citra wajah masukan untuk selanjutnya dilakukan deteksi bagian hidung dan mulut. Lalu ekstraksi ciri menggunakan GLCM dilakukan pada bagian hidung dan mulut tsb. untuk selanjutnya dilakukan pelatihan menggunakan Random Forest.

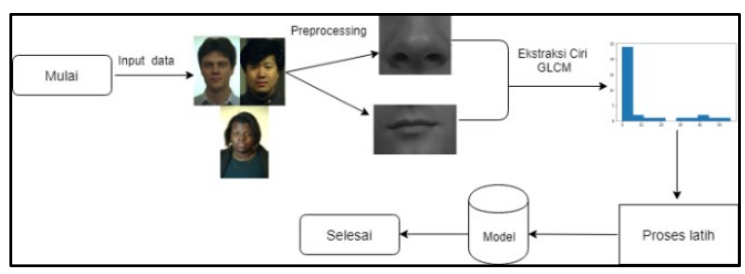

Gambar 1. Alur skema pelatihan

Sementara, alur skema pengujian pada Gambar 2 secara umum mirip dengan skema latih. Setelah mendapat masukan berupa citra wajah, sistem mendeteksi bagian hidung dan mulut untuk selanjutnya dilakukan ekstraksi ciri. Vektor ciri yang didapatkan dari hasil ekstraksi ciri selanjutnya dibandingkan dengan model latih (yang didapatkan sebelumnya pada tahap pelatihan) untuk mendapatkan hasil klasifikasi.

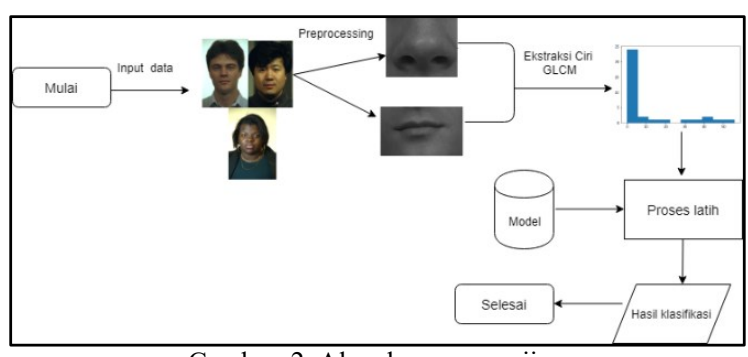

Gambar 2. Alur skema pengujian

\subsection{Prapemrosesan citra masukan}

Prapemrosesan yang dilakukan adalah melakukan deteksi bagian hidung dan mulut pada wajah menggunakan algoritma Viola-Jones (Viola \& Jones, 2001). Deteksi terhadap hidung dan mulut dilakukan berdasarkan eksperimen yang telah dilakukan oleh Momin \& Tapamo (2016) yang menyebutkan bahwa bagian hidung dan mulut merupakan indikator yang lebih baik dari mata.

\subsection{Ekstraksi Ciri menggunakan Gray Level Co- Occurrence Matrix (GLCM)}

GLCM adalah salah satu metode analisis tekstur yang paling dikenal yang menghitung ciri statistik berdasarkan intensitas tingkat keabuan citra (Hlaing \& Gopalakrishnan, 2016). GLCM termasuk ekstraksi ciri orde dua yang menghitung probabilitas hubungan ketetanggaan antara dua piksel pada jarak dan orientasi sudut tertentu. Jarak dinyatakan dalam piksel dan orientasi sudut dinyatakan dalam derajat $0^{\circ}, 45^{\circ}, 90^{\circ}$, dan $135^{\circ}$. GLCM memiliki 14 ciri (Haralick, Shanmugam, \& Dinstein, 1973) namun pada penelitian kali ini hanya digunakan enam ciri yang paling umum digunakan, yaitu energy, entropy, correlation, contras, homogeneity, dan dissimilarity.

1. Energy, merupakan nilai yang menunjukkan keteraturan intensitas piksel pada citra grayscale. Semakin teratur suatu citra maka nilai energy akan semakin tinggi. Rentang nilainya berada [0..1], dengan nilai 1 berarti citra konstan atau tidak berubah (Hlaing \& Gopalakrishnan, 2016). Energy dapat dilihat pada persamaan (1).

$$
\text { Energy }=\sum_{i, j=0}^{N_{g}-1} P(i, j)^{2}
$$

2. Homogeneity, menunjukan seberapa dekat intensitas piksel dengan piksel tetangganya. Rentang nilainya berada di [0..1] (Hlaing \& Gopalakrishnan, 2016). Homogeneity dapat dilihat pada persamaan (2).

$$
\begin{aligned}
& \text { Homogeneity } \\
& =\sum_{i, j=0}^{N_{g}-1} \frac{1}{1+(i-j)^{2}} P(i, j)
\end{aligned}
$$

3. Correlation, mengukur ketergantungan linear abu-abu antara piksel dalam dua arah yang berbeda (Hlaing \& Gopalakrishnan, 2016). Correlation dapat dilihat pada persamaan (3).

$$
\begin{aligned}
& \text { Corellation } \\
& =\frac{\sum_{i, j=0}^{N_{g}-1}(i-\mu)(j-\mu) P(i, j)}{\sigma_{i} \sigma_{j}}
\end{aligned}
$$

4. Contrast dapat dilihat pada persamaan (4), mengukur seberapa jauh perbedaan dari intensitas piksel tetangga. Saat contrast bernilai 0 , maka tidak terdapat perubahan intensitas piksel.

$$
\text { Contras }=\sum_{i, j=0}^{N_{g}-1}(i-j)^{2} P(i, j)
$$


5. Entropy dapat dilihat pada persamaan (5), mengukur kompleksitas atau kelainan suatu citra.

$$
\begin{aligned}
& \text { Entropy } \\
& =-\sum_{i, j=0}^{N_{g}-1} P(i, j)[\ln P(i, j)]
\end{aligned}
$$

6. Dissimilarity (6), mengukur ketidakmiripan suatu tekstur, yang akan bernilai besar bila acak dan sebaliknya akan bernilai kecil bila seragam.

$$
\text { Dissimilarity }=\sum_{\substack{i, j=0 \\-j \mid P(i, j)}}^{N_{g}-1} \mid i
$$

$P(i, j)$ adalah nilai normalisasi GLCM. Setiap $(i, j)$ adalah jumlah kemunculan pasangan, $i$ dan $j$ yang berjarak $d . N_{g}$ adalah nilai maksimum keabuan citra.

\subsection{Klasifikasi dengan Random Forest}

Random Forest (RF) adalah algoritma klasifikasi yang menggunakan ensemble learning yang dikembangkan oleh Breiman dan Cutler (2001). Random Forest merupakan kombinasi pohon keputusan sedemikian sehingga setiap pohon bergantung pada nilai-nilai vector acak yang melakukan sampling secara independent dengan distribusi yang sama untuk semua pohon dalam hutan tersebut. Kekuatan RF terletak pada seleksi ciri yang acak dalam pemilihan setiap simpul (node) yang mampu menghasilkan tingkat kesalahan relatif rendah (Boyseens \& Viriri, 2016). RF terbukti menghasilkan kinerja yang baik pada penelitian pengenalan ras dibandingkan dengan algoritma klasifikasi tanpa Bagging (Rehman, Khan, Siddiqi, Khan, \& Khan, 2018).

\section{HASIL EKSPERIMEN DAN ANALISIS}

Pada bagian ini dipaparkan data yang digunakan dalam eksperimen, analisis hasil deteksi hidung dan mulut, dan analisis pengaruh penggunaan ciri GLCM.

\subsection{Data}

Data yang digunakan merupakan dataset yang diambil dari Face Recognition Technology (FERET). Data ini terbagi ke dalam tiga kelas, yaitu Kaukasoid (667 citra), Mongoloid (192 citra) dan Negroid (108 citra) dengan total 967 citra, dengan posisi wajah pada citra berada pada posisi menghadap ke depan. Resolusi citra berukuran 512×768 piksel. Contoh beberapa citra yang terdapat dalam dataset dapat dilihat pada Gambar 3.

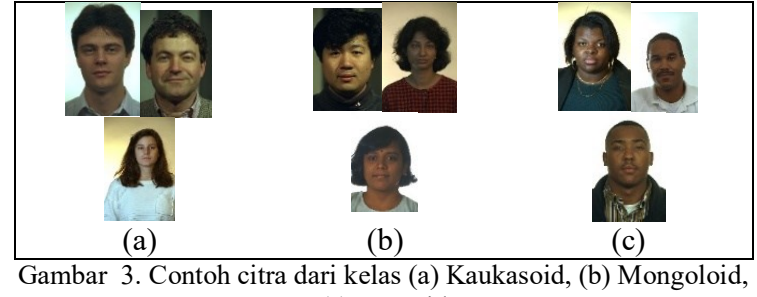

(c) Negroid

Kelas Kaukasoid merupakan kelompok ras dari wilayah negara Eropa atau yang berkulit putih. Mongoloid merupakan kelompok ras dari negara Asia dan Negroid merupakan kelompok ras AfrikaAmerika. Untuk keperluan eksperimen, data dibagi ke dalam data latih dan data uji dengan proporsi 70:30, sehingga didapat 676 citra latih dan 291 citra uji.

\subsection{Analisis Deteksi Hidung dan Mulut}

Pengenalan ras dilakukan menggunakan ciri yang diekstrak dari bagian hidung dan mulut. Proses deteksi bagian hidung dan mulut dilakukan menggunakan algoritma Viola Jones. Pada proses deteksi hidung, terdapat 22 citra yang salah dideteksi bagian hidungnya, dari 291 citra uji. Sementara, pada proses deteksi mulut, terdapat 57 citra yang salah dideteksi. Contoh hasil deteksi bagian mulut dan/atau hidung dapat dilihat pada Tabel 2.

Tabel 2. Contoh hasil deteksi hidung dan mulut

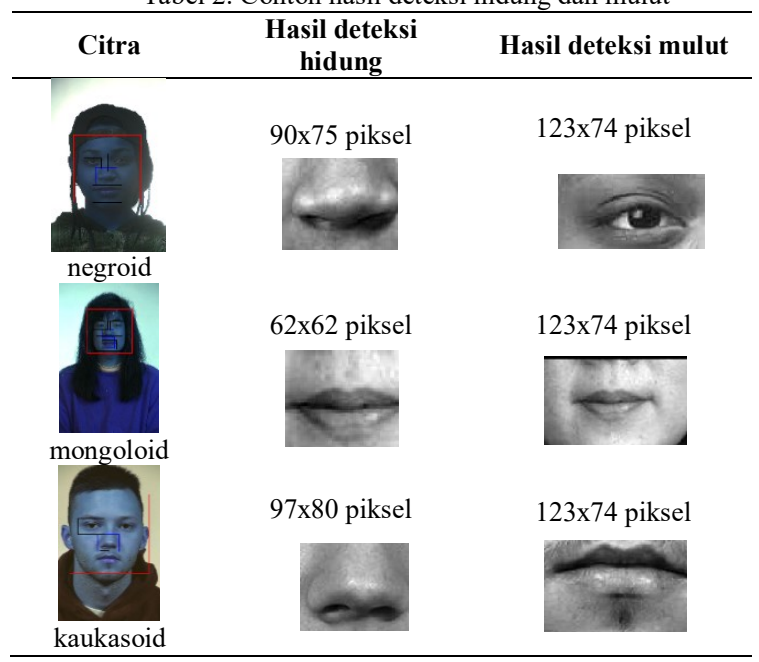

Selanjutnya, ektraksi ciri menggunakan GLCM diterapkan pada citra hidung dan mulut ini untuk selanjutnya diklasifikasi menggunakan Random Forest, dengan parameter jumlah pohon $=100$. Eksperimen ini dilakukan dengan tujuan untuk mengetahui bagian wajah apa yang paling baik digunakan. Dari hasil pengujian terhadap 291 citra uji yang terdapat pada Gambar 4, dapat dilihat bahwa penggunaan bagian wajah hidung dan mulut mendapatkan akurasi yang paling baik, yaitu 77,31\%. Ciri GLCM yang digunakan adalah entropy, energy, contras, correlation, homogeneity, dan dissimilarity. 


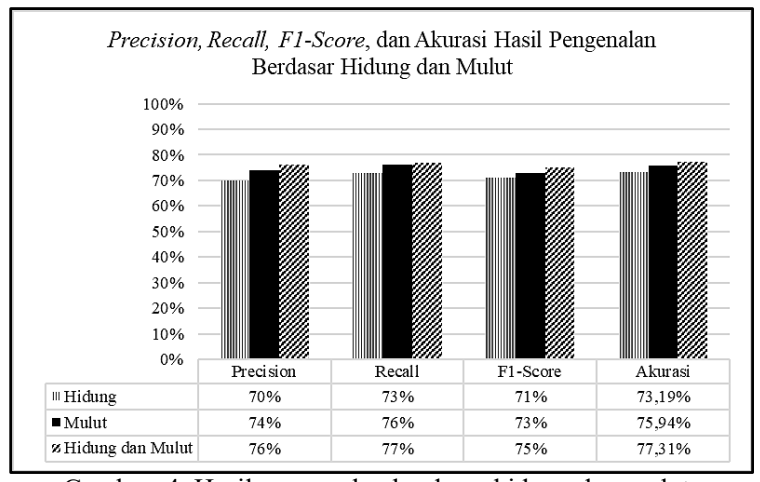

Gambar 4. Hasil pengenalan berdasar hidung dan mulut

\subsection{Analisis Pengaruh Penggunaan Ciri GLCM}

Pada bagian ini eksperimen dilakukan untuk mengetahui pengaruh penggunaan ciri GLCM pada hasil klasifikasi. Meskipun GLCM memiliki 14 ciri namun hanya enam ciri global yang sering digunakan yaitu entropy, energy, contras, homogeneity, dissimilarity dan correlation. Parameter sudut yang digunakan adalah $0^{\circ}, 45^{\circ}, 90^{\circ}$, dan $135^{\circ}$ dan jarak $=1$. Pada penelitian ini dilakukan uji coba terhadap kombinasi enam ciri tersebut yang terbagi ke dalam 10 skenario seperti terlihat pada Tabel 3 .

Dari hasil pengujian yang tertera pada Gambar 5, dapat dilihat bahwa skenario-9 memiliki akurasi paling tinggi yaitu dengan nilai akurasi $79,04 \%$. Sementara hasil pengujian menggunakan enam ciri seperti pada skenario-10, akurasi yang didapat lebih rendah yaitu $77,31 \%$.

Tabel 3. Skenario pengujian ekstraksi ciri

\begin{tabular}{ll}
\hline \multicolumn{1}{c}{ Skenario } & \multicolumn{1}{c}{ Ciri yang digunakan } \\
\hline Skenario-1 & Entropy \\
Skenario-2 & Energy \\
Skenario-3 & Contras \\
Skenario-4 & Corellation \\
Skenario-5 & Homogeneity \\
Skenario-6 & Dissmilarity \\
Skenario-7 & $\begin{array}{l}\text { Entropy, energy, correlation, } \\
\text { danhomogeneity (Boyseens \& Viriri, 2016) }\end{array}$ \\
Skenario-8 & $\begin{array}{l}\text { Entropy, energy, correlation, homogeneity, } \\
\text { dan contrast (Bianconi, Smeraldi, }\end{array}$ \\
& $\begin{array}{l}\text { Abdollahyan, \& Xiao, 2016) } \\
\text { Dissimilarity, energy, contras, correlation, } \\
\text { dan homogeneity } \\
\text { Skenario-9 }\end{array}$ \\
Skenario-10 & homogeneity, dan dissimilarity \\
&
\end{tabular}

Gambar 6 merupakan confusion matrix dari skenario 9 dengan perolehan akurasi yaitu 79.04\%, F1-score $77 \%$, precision $78 \%$, dan recall $79 \%$. Nilai TP (True Positive) dari kelas Kaukasoid adalah paling tinggi, yaitu 196 citra karena jumlah kelas Kaukasoid pada dataset memang paling banyak. Terdapat 7 (tujuh) citra yang diprediksi sebagai Mongoloid, dengan 2 (dua) citra di antaranya salah dalam pendeteksian hidung dan mulut. Sementara 5 (lima) citra lainnya memiliki nilai vektor ciri yang sangat mirip dengan vektor ciri kelas Mongoloid. Selain itu terdapat 4 (empat) citra yang salah diprediksi sebagai Negroid: satu citra salah dalam hasil deteksi hidung dan mulut, satu citra salah dalam mendeteksi mulut, dan dua citra lain memiliki nilai vektor ciri yang hampir sama dengan kelas Negroid.

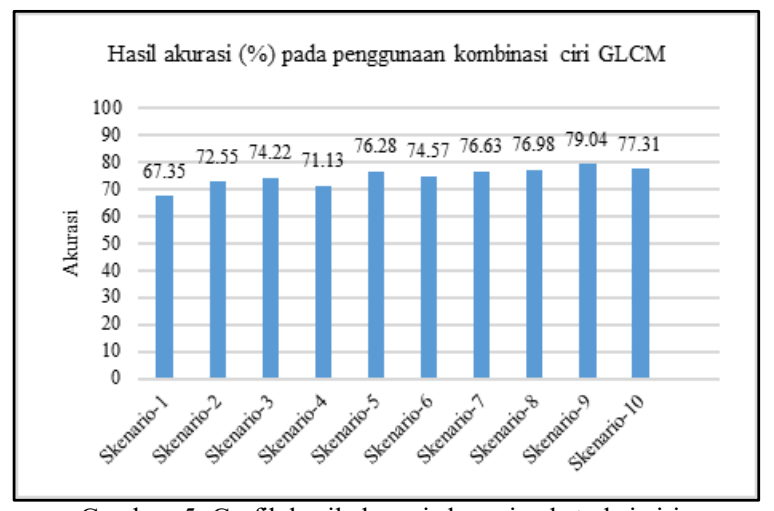

Gambar 5. Grafik hasil akurasi skenario ekstraksi ciri

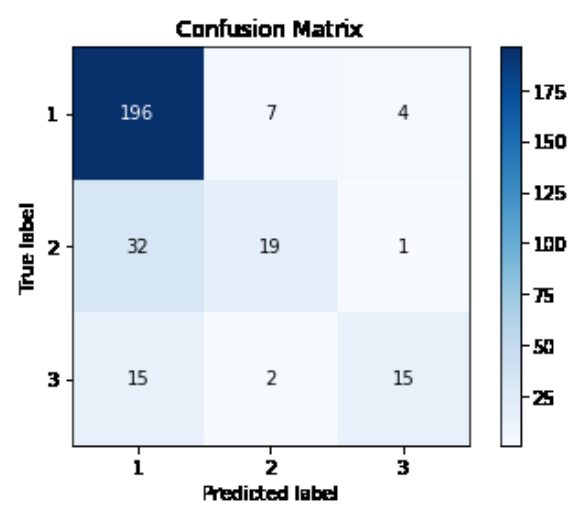

Gambar 6. Confusion matrix skenario-9. Label 1= Kaukasoid, label 2=Mongoloid, label 3=Negroid

Sementara itu, pada kelas Mongoloid, terdapat 32 citra yang terprediksi sebagai Kaukasoid: dua citra salah dalam hasil deteksi hidung, tujuh citra salah dalam hasil deteksi mulut, dua citra salah dalam hasil deteksi hidung dan mulut, sedangkan 21 citra yang hasil deteksi hidung dan mulutnya benar memiliki nilai vektor ciri yang hampir sama dengan kelas Kaukasoid. Kelas Mongoloid yang terprediksi sebagai Negroid hanya ada satu citra. Citra tersebut dapat mendeteksi hidung dan mulut tetapi nilai vektor cirinya hampir sama dengan kelas Negroid sehingga citra tersebut terdeteksi sebagai kelas Negroid.

Pada kelas Negroid yang terprediksi sebagai Kaukasoid ada 15 citra: dua citra salah dalam deteksi mulut, 13 citra dapat mendeteksi hidung dan mulut dengan baik namun nilai vektor cirinya hampir sama dengan kelas Kaukasoid sehingga terprediksi menjadi kelas Kaukasoid. Pada kelas Negroid yang terprediksi sebagai Mongoloid terdapat dua citra, dua citra ini dapat mendeteksi hidung dan mulut namun hasil nilai vektor cirinya hampir sama dengan kelas Mongoloid sehingga terprediksi sebagai kelas Mongoloid.

Pada penelitian ini juga dilakukan perhitungan akurasi menggunakan classifier k-nearest neighbor (KNN) untuk dibandingkan dengan Random Forest. Gambar 7 menunjukkan hasil perbandingan nilai 
akurasi dan f1-score dari KNN dan Random Forest. Dapat dilihat bahwa KNN mendapatkan nilai akurasi 73,15\% dan F1-Score 69\%, lebih rendah dibanding akurasi menggunakan Random Forest yaitu 79,04\% dengan F1-score sebesar 76\%. Dari hasil tersebut dapat dilihat bahwa penggunaan algoritma klasifikasi Random Forest lebih baik dibandingkan dengan KNN.

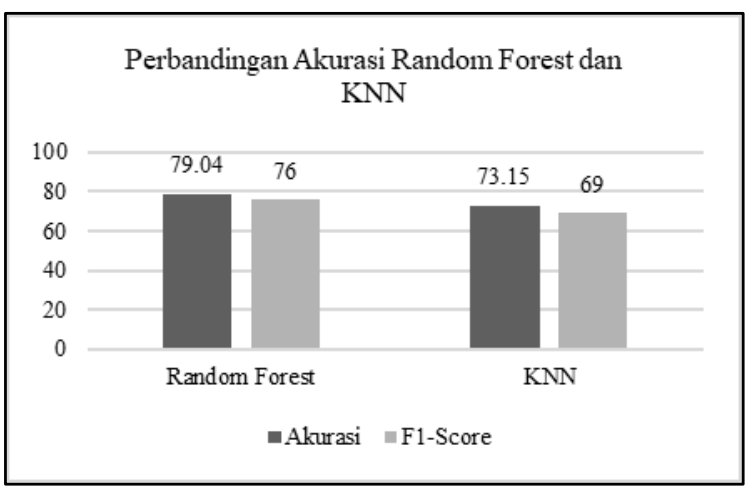

Gambar 7. Perbandingan akurasi Random Forest dan KNN

\section{KESIMPULAN}

Dari hasil eksperimen yang dilakukan terbukti didapatkan hasil bahwa kombinasi ciri yang diekstrak dari hidung dan mulut mampu meningkatkan akurasi pengenalan ras. Selain itu, penggunaan 5 (lima) fitur GLCM (dissimilarity, energy, contras, correlation, dan homogeneity) mampu menghasilkan akurasi pengenalan yang lebih baik dibandingkan dengan penggunaan keseluruhan fitur GLCM.

\section{DAFTAR PUSTAKA}

ALRASHED, H. F., dan BERBAR, M. A., 2013. Facial Gender Recognition Using Eyes Images. Int. J. Adv. Res. Comput. Commun. Eng., vol. 2, no. 6, pp. 2441-2445.

BOYSEENS, A. dan VIRIRI, S. B., 2016. Component-Based Ethnicity Identification. pp. 293-303.

BIANCONI, F., SMERALDI, F., ABDOLLAHYAN, M., dan XIAO, P., 2016. On the use of skin texture features for gender recognition : an experimental evaluation.

BREIMAN, L., 2001. Random Forests, Mach. Learn., vol. 45 , no. 1 , pp. $5-32$

ELEYAN, A. dan DEMIREL, H., 2011. Cooccurrence matrix and its statistical features as a new approach for face recognition. Turk J Elec Eng Comp Sci, vol. 19, no. 1, pp. 97107.

HARALICK, R. M., SHANMUGAM, K., dan DINSTEIN, I., 1973. Textural features for image classification. IEEE Trans. Syst. Man.
Cybern., vol. SMC-3, no. 6, pp. 610-621

HLAING, K. N. N. dan GOPALAKRISHNAN, A. K., 2016. Myanmar paper currency recognition using GLCM and k-NN. 2016 2nd Asian Conference on Defence Technology, ACDT 2016.

HOSOI, S., TAKIKAWA, E., dan KAWADE, M., 2004. Ethnicity estimation with facial images. Proceedings - Sixth IEEE International Conference on Automatic Face and Gesture Recognition.

MANESH, F.S., GHAHRAMANI, M., dan TAN, Y. P., 2010. Facial part displacement effect on template-based gender and ethnicity classification. 11th International Conference on Control, Automation, Robotics and Vision, ICARCV 2010.

MASOOD, S., GUPTA, S., WAJID, A., GUPTA, S., dan AHMED, M., 2018. Prediction of human ethnicity from facial images using neural networks. Advances in Intelligent Systems and Computing, vol. 542, pp. 217-226.

MOMIN, H. dan TAPAMO, J. R., 2016. A comparative study of a face components based model of ethnic classification using gabor filters. Appl. Math. Inf. Sci., vol. 10, no. 6, pp. 2255-2265,

REHMAN, A., KHAN, G., SIDDIQI, A., KHAN, A., dan KHAN, U. G., 2018. Modified texture features from histogram and gray level cooccurence matrix of facial data for ethnicity detection. 5th International Multi-Topic ICT Conference: Technologies For Future Generations, IMTIC 2018 - Proceedings, pp. $1-6$.

STHEVANIE, F., RAMADHANI, K. N., dan RASYID, H. F., 2018. Klasifikasi Ras Mongoloid Berbasis Citra Wajah menggunakan Algoritma k-Nearest Neighbors. Indones. J. Comput., vol. 3, no. 1, p. 45.

YANG, Z. dan AI, H., 2007. Demographic classification with local binary patterns. Lecture Notes in Computer Science (including subseries Lecture Notes in Artificial Intelligence and Lecture Notes in Bioinformatics).

VIOLA, P. dan JONES, M., 2001. Rapid object detection using a boosted cascade of simple features. Proceedings of the IEEE Computer Society Conference on Computer Vision and Pattern Recognition, , vol. 1. 